\title{
PATIENT SATISFACTION AND COST ANALYSIS OF ANALGESIA MANAGEMENT FOR POST-OPERATIVE PROCEDURES IN HTAA: PCA VS. CONVENTIONAL METHOD
}

\author{
Siti Norsyuhada Ramli ${ }^{1}$, Muhammad Alif Mazlan ${ }^{1}$, Afzan Mat Yusof ${ }^{1,2}$ and Muhammad Lokman Md. Isa ${ }^{1,2}$. \\ ${ }^{1}$ Department Basic Medical Sciences, Kulliyyah of Nursing, ${ }^{2}$ Human Molecular and Cellular Biology Research Cluster (iMoleC), \\ International Islamic University Malaysia, Jalan Sultan Ahmad Shah Bandar Indera Mahkota 25200 Kuantan, Pahang, \\ Malaysia.
}

Corresponding author: Muhammad Lokman Md Isa

Email: lokman@iium.edu.my

\begin{abstract}
Acute pain service (APS) offer several techniques to the post-operative patient in controlling and relieving the pain such as intravenous infusion, patient-controlled analgesia, epidural infusion, subcutaneous or intramuscular injection and intrathecal administration. The effectiveness of and satisfaction towards APS is not clearly defined. Therefore, the aim of this study is to conduct the cost analysis and comparison between these techniques and patient satisfaction. The study design for cost analysis was retrospective study. The means of the data were calculated based on Integration Store of Hospital Tengku Ampuan Afzan records. In addition, the evaluation of patient's satisfaction was conducted by using a crosssectional study design. The mean of the data was calculated and analysed by using Chi-square test. The total cost required to prepare PCA for post-operative patient was the highest with RM 8810.98. Meanwhile, the cost for subcutaneous morphine injection, epidural infusion and peripheral block injection were RM 2.11, RM 5323.95 and RM 4.95 respectively. However, when taking into the aspect of patient's satisfaction, PCA has the highest level of excellent performance with $54.6 \%$ compare to EDA (33\%) and BLOCK (12.4\%) with the p-value is less than 0.05 . In conclusion, every drug has its own side effects. As the healthcare provider, it is a need to ensure drugs that were given to the patients are at the very minimum risk of having the side effects. Based on the findings of this study, it could be said that both drugs have lower percentage of people experienced the side effect after treated with the drugs. Therefore, the future study should be more focusing on the side effect of the drugs used. In terms of cost spent for the methods, the PCA regimen is more likely expensive compared to the conventional methods. However, based on survey among the patients, PCA-treated patients expressed higher satisfaction compared to the conventional regimen of pain management.
\end{abstract}

Keywords: Patient-controlled analgesia, post-operative, pain management, cost effective, patient's satisfaction

\section{INTRODUCTION}

Post-operative management is very crucial to ensure the patients that underwent the surgical procedures have good prognosis. Most probably, the patients will suffer pain after the surgeries because the anaesthetic effect has gone. The post-operative pain may interrupt the recovery and discharge process. Meanwhile, it also can lead to chronic pain and other complications. Moreover, insufficient pain relief can have psychological, physiological and socioeconomic consequences that can affect patient suffering, clinical outcome and increase the financial $\operatorname{costs}^{1}$. Therefore, the pain management in the hospital or clinics could be the indicator for evaluating the patients' satisfaction.

Acute Pain Services (APS) has been established as a method in improving the pain control and management among the postoperative patients. There are several types of techniques offered such as intravenous infusion, patient-controlled analgesic, subcutaneous or intramuscular injection, epidural infusion and intrathecal administration.
Most of postoperative analgesic regimens demand by a patient is to self-administer analgesics for example patient-controlled analgesia (PCA). PCA has been steadily gaining acceptance in the treatment of postoperative pain ${ }^{2}$. PCA is improving in terms of usage and satisfactions since patients are independently push the button of the device in consuming the amount of analgesic needed for their own pain sensation theoretically.

Despite the availability of clinical practice guidelines, effective analgesics and new technologies for drug administration, the management of post-operative pain continues to remain problematic and unsatisfactory ${ }^{3}$. Compared with conventional opioids analgesia for postoperative pain, PCA has been found to provide better analgesia and give patients a sense of control over their pain management which could help to reduce their feelings of weakness and susceptibility $^{2}$. Although PCA provides good pain control, some patients may be less satisfied with this method of pain management in term of cost incur from this method. This is because the PCA pain 
management was significantly more expensive than another pain management ${ }^{2}$.

The study concerning the effectiveness of PCA in pain management in comparison with other techniques is not clearly established. The rationale for this study is to make an analysis of comparing between PCA and the conventional techniques as post-operative pain management in terms of the pain relief, side effects, and patient's satisfaction. Herein, this study was conducted to analyse the cost and patient's satisfaction towards the acute pain services as post-operative pain management by comparing patient-controlled analgesia with conventional analgesia regimens.

\section{METHODS}

\section{Cost analysis study}

The study design was used in this post-operative pain management was a retrospective study. The records of the data were obtained from Integration Store of Hospital Tengku Ampuan Afzan (HTAA), Kuantan, Pahang once approved by the authority of the hospital. The cost analysis for post-operative pain managements was compared based on the expenditure records and documents of the Anaesthesia Clinic. The total cost that involved each of the pain management regimens were calculated. The mean for each pain management regimens were obtained. The cost calculation in this study was including the consumable, drug and equipment cost. In addition, this study focused on methods that demonstrate the highest frequency of posing no side effect.

\section{Patient's satisfaction study}

A cross-sectional study was conducted by distributing the questionnaires. The questionnaires were adapted and modified from the Pain Evaluation Form of the clinic. This form was used in the clinic to evaluate the patient's satisfaction concerning the pain management regimes. Formerly, the set of questionnaires was tested for the validity and reliability in order to ensure the respondents will understand the questionnaires. In this study, the respondents were recruited both male and female. The patients were admitted in surgical, orthopaedic, and gynaecology wards of the HTAA.

\section{Inclusion and exclusion criteria}

In general, the participants of this study should be age above 18 years old within three days postoperative and treated with acute pain services. Exclusively for the patient's satisfaction survey, the participant must be able to understand either Malay or English languages.
Meanwhile, those patients that experienced the surgeries is one of the exclusion criteria for this study. In addition, patients that have experience in drug abuse or have the psychiatric problem were also excluded. Mothers that undergone lower segment Caesarean section (LSCS) also have been excluded.

\section{Ethical consideration}

The ethical consideration has been approved by Kulliyyah of Nursing Research Committee (KNRC), International Islamic University of Malaysia Research Ethics Committee (IREC), National Medical Research Registration (NMMR) and Clinical Research Centre (CRC) of Hospital Tengku Ampuan Afzan (HTAA).

\section{Data analysis}

Statistical Package for Social Science (SPSS) software was used to analyse the collected data. In this study, the Chi-square test has been applied for the cost analysis and cross-sectional study. Firstly, for the retrospective study all documents and records were read. Then, the cost of the consumable and drugs were calculated. Based on the data, table and diagram were constructed. The cost and satisfaction were evaluated from the available data. If the drugs showed no significant different in terms of patient satisfaction, the cheaper drug was the best drugs to be chosen. In contrast, if the drugs were significantly difference to each other, the cost were calculated based on the number of satisfied patients. Secondly, from the cross-sectional study, the socio-demographic data was described in a table. In addition, the association of the socio-demographic factors with the patients' satisfaction were determined based on Chi-square test. All tests were two-tailed and a pvalue $<0.05$ was accepted as statistically significant.

\section{RESULTS}

\section{Retrospective study}

From the Figure 1, it showed that out of 350 analysed forms, 182 patients have used PCA, 126 used EDA, 30 of them were used BLOCK and the remaining 12 patients were serviced with $\mathrm{SCM}$. The Table 1 shows the total cost of using PCA and conventional analgesia regimens based on year 2013. The total cost required to prepare PCA for post-operative patient is RM 8810.98. Meanwhile, the cost for SCM, EDA, and BLOCK are RM 2.11, RM 5323.95 and RM 4.95 respectively. The mean of the total cost of each pain management regimens are RM 48.41, RM 0.18, RM 42.25, and RM 0.17 for PCA, SCM, EDA, and BLOCK respectively.

Table 2 showed the number of patients based on side effect during receiving the services of acute pain management. Majority of EDA and PCA patients do not experienced any side effect with the 
highest percentage of $92.9 \%$ and $78.0 \%$ respectively). Meanwhile, Table 3 shows the pain score frequency for PCA and EDA used by postoperative patients. The pain score was rated with four indicators which are painless (pain score $=0$ ), mild (pain score $=1-3$ ), moderate (pain score $=4-6$ ) and severe pain (pain score $=7-10$ ). Most of PCA patient were rated pain score at 4 , meanwhile EDA at 3. Pain is very subjective which is very difficult to know what were the exact pain score of the patients. Occasionally, the patients could be confusing which degree of their pain. Therefore, the pain score 3 and 4 are still tolerable which are very mild and moderate pain respectively.

\section{Socio-demographic data}

A total of 168 respondents were enrolled in this study. 73 of patients were used PCA, meanwhile 75 of them was treated with EDA, and 20 were using BLOCK (Figure 1). Table 4 shows the frequency distribution of post-operative patient's characteristics. Since the patients consisted of various level of age, they have been grouped into three classes which are young adult (aged 18-34 years old), middle-age adult (aged 35-59 years old), and older adult (aged 60 years old and above). The highest category of age of the patients was middle age adult with $49.3 \%$, followed with young adult and older adult with percentage of $26.0 \%$ and $24.7 \%$ respectively. The percentages of male and female patients are $58.9 \%$ and $41.1 \%$ respectively. Then, according to the marital status, married patient has the majority with $78 \%$ and single patients with the percentage of $22 \%$. With regard to the level of education, this factor has been categorized into several groups which are primary level (standard 1 until standard 6), secondary level (form 1 until form 5), higher level (certificate, diploma, degree, master and $\mathrm{PhD}$ ), and never been to school. This study discovered that out of 168 patients, $48.2 \%$ received secondary level of education, $23.8 \%$ received primary education, and $16.1 \%$ received higher education. Meanwhile, the remaining $11.9 \%$ never received any education.

\section{Association of sociodemographic factors with patients' satisfaction}

Table 5 shows the association between patients' satisfaction towards post-operative pain management with sociodemographic factors. Among the respondents, most of them were from middle age (35-59 years old) people. In comparison with the other groups, the middle age group showed the highest satisfaction. For age factor, there was significant different between age groups and level of patient's satisfaction as indicated by the $p$-value of 0.024 . In addition, in terms of gender the most male patients rated the pain management offered by healthcare provider as excellent, meanwhile majority of female just rated it as good and satisfied only.

The $p$-value was 0.014 which it was showing the significant different between gender and patients' satisfaction. Based on educational level, majority of patient that has secondary education rated the APS as excellent and good. Meanwhile for the satisfied level, the frequency was rated same by patients with primary, secondary and never been to school. Thus, there was significant different between educational level and level of patient's satisfaction as indicated by the $p$-value of 0.030 . The association between marital status and level of satisfaction among post-operative patient that used APS showed that all level of satisfaction has higher frequency rated by married patients. There was significant different between educational level and level of patient's satisfaction as indicated by the $p$-value of 0.012 .

\section{Satisfaction score}

In this study, the satisfaction score was categorized with three which were excellent, good and satisfied. Based on Table 6, the PCA was the highest rated with excellent and followed by EDA and BLOCK. Among the patients that were treated with PCA, most of them were satisfied with the pain management after the surgery. However, the satisfaction score of patients treated with EDA showed that most of the patients also rated excellent for the treatment. The differences between the PCA and EDA showed that the percentage of the PCA-treated patient group was the higher compared to EDA-treated patient group. There was significant different between the level of patient's satisfaction with type of APS as indicated by the $p$-value of 0.004 which it lesser than 0.05 . 
A

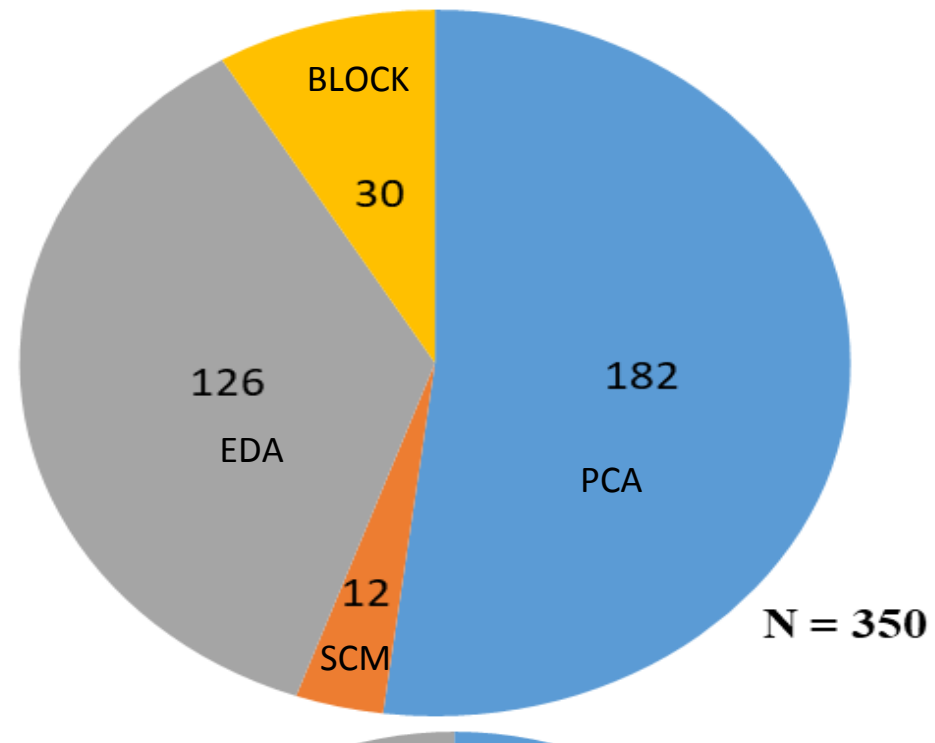

B

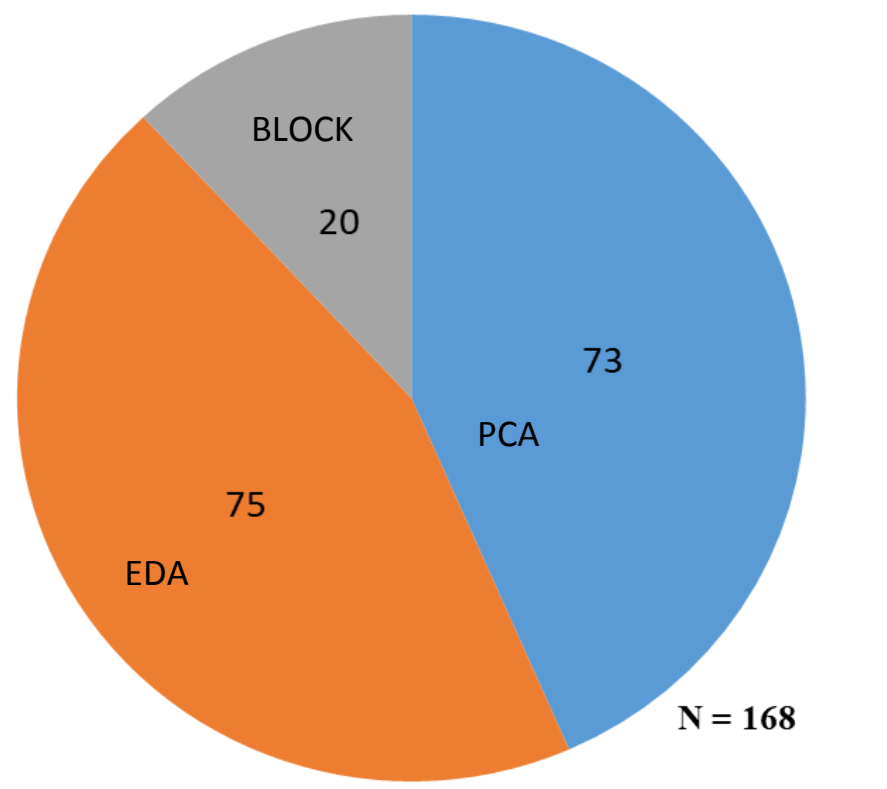

Figure 1: The distribution of APS for post-operative patients: The distribution based on patient hospital record (A). The distribution of post-operative patient received different types of APS obtained from cross-sectional study (B)

\section{DISCUSSION}

Based on this retrospective study, the total cost incurred in managing post-operative patient was higher by using PCA method compared to conventional method. EDA also poses a high cost, but it is cheaper than PCA. Both PCA and conventional methods demonstrate the presence of side effects. In this study, majority of PCA patients do not experienced any side effect similarly to the conventional analgesia regimens. A study reported that the using of PCA with morphine was effective to control post-operative pain with few side effects ${ }^{4}$. In contrast, a study reported that nausea, vomiting, sedation, pruritus, and urinary retention happened with both PCA and control treatments but there was no evidence of any difference between the two analgesic techniques ${ }^{5}$. Even so, further evaluation is needed to explain the factors that cause side effects.

In addition, in terms of pain score of EDA is better compared to PCA. This finding was obtained according to the pain score rated by the patients. The pain score of the majority of the patients treated with EDA and PCA were three and four respectively. This pain scoring is according to zero to ten pain severity ${ }^{6}$. Based on this study, PCA is much better in relieving pain compared to SCM method. It was supported by a study which is the PCA regimen achieved lower pain score compared to SCM method. In contrast, there is one study reported that SCM regimen was a satisfactory alternative to PCA morphine among the cardiac 
surgery patients ${ }^{7}$. A study had also reported that post-operative patients treated with PCA showed significant better pain relief during the first 24 hours compare to those who received intramuscular injection pain management ${ }^{2}$. Furthermore, the type of surgeries also may influence the patient's pain score. For instance, a study reported that the patients with abdominal surgery had better pain relief with PCA than with conventional analgesia ${ }^{8}$.

Table 1: Total cost of PCA and Conventional Analgesia Regimens in 2013

\begin{tabular}{|c|c|c|c|c|}
\hline & \multirow[t]{2}{*}{ PCA $(\mathrm{N}=182)$} & \multicolumn{3}{|c|}{ Conventional Analgesia } \\
\hline & & $\mathrm{SCM}(\mathrm{N}=12)$ & $\operatorname{EDA}(\mathrm{N}=126)$ & $\operatorname{BLOCK}(\mathrm{N}=30)$ \\
\hline \multicolumn{5}{|l|}{ Medical devices } \\
\hline - Disposable gloves & 0.44 & 0.44 & 0.44 & \\
\hline - Sterile gloves & - & - & - & 1.75 \\
\hline - $\quad$ Syringe $5 \mathrm{ml}$ & - & 0.30 & - & 0.30 \\
\hline - $\quad$ Syringe $10 \mathrm{ml}$ & - & - & - & 1.00 \\
\hline - $\quad$ Syringe $50 \mathrm{ml}$ & 4.00 & - & 4.00 & - \\
\hline - PCA device & 8800.00 & - & - & - \\
\hline _ Infusion pump & - & - & 5300.00 & - \\
\hline - Tubing & 0.25 & - & 0.25 & - \\
\hline - Needle & 0.07 & 0.07 & 0.07 & 0.07 \\
\hline $\begin{array}{l}\text { Subtotal medical devices } \\
\text { (RM) }\end{array}$ & 8804.76 & 0.81 & 5304.76 & 3.12 \\
\hline Drugs & & & & \\
\hline $\begin{array}{l}\text { - } \quad \text { Lidocaine } 10 \\
\mathrm{mg} / 10 \mathrm{ml}\end{array}$ & - & - & - & 1.83 \\
\hline $\begin{array}{l}\text { Morphine } \\
10 \mathrm{mg} / 1 \mathrm{ml}\end{array}$ & 3.72 & 1.30 & - & - \\
\hline $\begin{array}{l}\text { - } \quad \text { Phentanyl } \\
0.1 \mathrm{mg} / 2 \mathrm{ml}\end{array}$ & - & - & 1.59 & - \\
\hline $\begin{array}{l}\text { Ropivacaine } \\
2 \mathrm{mg} / \mathrm{ml}\end{array}$ & - & - & 15.10 & - \\
\hline - $\mathrm{NaCl} 0.9 \% 500 \mathrm{ml}$ & 2.50 & - & 2.50 & - \\
\hline Subtotal drugs (RM) & 6.22 & 1.30 & 19.19 & 1.83 \\
\hline Total Cost (RM) & 8810.98 & 2.11 & 5323.95 & 4.95 \\
\hline Cost per Patient (RM) & 48.41 & 0.18 & 42.25 & 0.17 \\
\hline
\end{tabular}

Table 2: Side Effect of Analgesia according to APS technique

\begin{tabular}{|c|c|c|c|c|c|c|c|c|c|}
\hline & \multicolumn{2}{|c|}{ PCA $(N=182)$} & \multicolumn{6}{|c|}{ Conventional Analgesia } & \multirow{3}{*}{$p$-value } \\
\hline & \multirow[b]{2}{*}{$f$} & \multirow[b]{2}{*}{$\%$} & \multicolumn{2}{|c|}{$\operatorname{SCM}(N=12)$} & \multicolumn{2}{|c|}{$\operatorname{EDA}(\mathrm{N}=126)$} & \multicolumn{2}{|c|}{ BLOCK } & \\
\hline & & & $f$ & $\%$ & $f$ & $\%$ & $f$ & $\%$ & \\
\hline Side Effect & & & & & & & & & \\
\hline NO & 142 & 78.0 & 10 & 83.3 & 117 & 92.9 & 30 & 100 & $0.001^{*}$ \\
\hline YES & 40 & 22.0 & 2 & 16.7 & 9 & 7.1 & - & - & \\
\hline
\end{tabular}

*Likelihood ratio 
Table 3: Pain Score according to APS type Used by Patients

\begin{tabular}{|c|c|c|c|c|c|c|c|c|}
\hline & \multicolumn{2}{|c|}{ PCA } & \multicolumn{2}{|c|}{$\begin{array}{l}\text { Frequency } \\
\text { Conventional Analgesia } \\
\text { EDA }\end{array}$} & \multicolumn{2}{|c|}{$\begin{array}{l}\text { SCM \& } \\
\text { BLOCK }\end{array}$} & \multirow[t]{2}{*}{ Total } & \multirow[t]{2}{*}{$p$-value } \\
\hline & $f$ & $\%$ & $f$ & $\%$ & $f$ & $\%$ & & \\
\hline \multicolumn{9}{|l|}{ Pain Score } \\
\hline$-\quad 1$ & 4 & 2.2 & 5 & 4.0 & & & 18 & \\
\hline-2 & 17 & 9.3 & 24 & 19.0 & & & 47 & \\
\hline-3 & 47 & 25.8 & 40 & 31.7 & & & 101 & $0.001^{*}$ \\
\hline-4 & 65 & 35.7 & 32 & 25.4 & $N A^{* *}$ & $N A^{* *}$ & 102 & \\
\hline-5 & 36 & 19.8 & 20 & 15.9 & & & 64 & \\
\hline-6 & 10 & 5.5 & 3 & 2.4 & & & 13 & \\
\hline 7 & 3 & 1.6 & 2 & 1.6 & & & 5 & \\
\hline Total & \multicolumn{2}{|c|}{182} & \multicolumn{2}{|c|}{126} & \multicolumn{2}{|c|}{42} & 350 & \\
\hline
\end{tabular}

Table 4: Descriptive data of patients

\begin{tabular}{|c|c|c|c|c|c|}
\hline \multirow{3}{*}{\multicolumn{2}{|c|}{ Variables }} & \multirow{2}{*}{\multicolumn{3}{|c|}{ Frequency $(N=168)$}} & \multirow[t]{3}{*}{ Percentage (\%) } \\
\hline & & & & al Analgesia & \\
\hline & & $\operatorname{PCA}(n=73)$ & $\operatorname{EDA}(n=75)$ & BLOCK $(n=20)$ & \\
\hline \multicolumn{6}{|c|}{ Age (year) } \\
\hline & Young Adult (18-34) & 19 & 19 & 8 & 26.0 \\
\hline & Middle Age (35-59) & 36 & 34 & 10 & 49.3 \\
\hline & $\begin{array}{l}\text { Older Adult ( } 60 \text { and } \\
\text { above) }\end{array}$ & 18 & 22 & 2 & 24.7 \\
\hline \multicolumn{6}{|c|}{ Gender } \\
\hline & Male & 43 & 31 & 12 & 58.9 \\
\hline & Female & 30 & 44 & 8 & 41.1 \\
\hline \multicolumn{6}{|c|}{ Marital Status } \\
\hline . & Single & 14 & 15 & 8 & 22.0 \\
\hline & Married & 59 & 60 & 12 & 78.0 \\
\hline \multicolumn{6}{|c|}{ Education Level } \\
\hline & Primary & 17 & 21 & 2 & 23.8 \\
\hline & Secondary & 36 & 30 & 15 & 48.2 \\
\hline & Higher & 11 & 13 & 3 & 16.1 \\
\hline 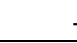 & Never & 9 & 11 & $\mathrm{Nil}$ & 11.9 \\
\hline
\end{tabular}

The satisfaction of the patients concerning the pain management is very important. 168 respondents were enrolled in this study. This study found a significant association between age groups with level of satisfaction as evidence by the $p$-value 0.024 . Middle age adult group more satisfied with APS by rating it as excellent $(49.3 \%)$, followed by young adult $(26.0 \%)$ and then older adult group $(24.7 \%)$. This is may be because middle age adult and young adult more understand about the using and effectiveness of pain management provide by hospital. It could be implied that the middle age group is more concern about their pain compared to other age group. However, it could be the aging process caused the senses become less sharp?. In addition, the young cancer patients may experience greater distress compare to the older patients because of the effect of serious illness on their life, possibly reflecting higher pain level reports ${ }^{10}$. Meanwhile, elderly patients have been noted to be more susceptive to the effects of opioid analgesia than young patients, and some phases of pharmacokinetics are affected in aging, such as distribution, metabolism, and elimination ${ }^{11}$. This factor will contribute to greater pain experienced by older people; thus, they could be rating APS as less excellent.

Female patients have rated APS less excellent may be due to the female patient cannot tolerate pain well compared to male patient. Experimental studies were reported that women have lower pain thresholds, higher pain ratings and less tolerance to the stimuli that causing pain ${ }^{12}$. Female patients were found to have more post-operative pain in several studies with coefficient of regression range: 
0.22 to 0.7911 . In addition, female patients were still concerned about pain post-surgery $(60 \%)$ but men indicated the improvement of their condition $^{13}$. Meanwhile, the gender role might be one of the factors that caused female are less tolerance towards pain compared to male. There is one study reported those who considered themselves more masculine and less sensitive to pain than the typical man showed higher pain tolerances ${ }^{14}$.

Table 5: Association between socio-demographic factors and patients' satisfaction

\begin{tabular}{|c|c|c|c|c|c|c|c|}
\hline & & & \multicolumn{3}{|c|}{ Level of Satisfaction } & \multirow[t]{2}{*}{ Total } & \multirow[t]{2}{*}{$p$-value } \\
\hline & & & Excellent & Good & Satisfied & & \\
\hline \multirow[t]{4}{*}{ Age Group } & - & Young Adult & 35 & 10 & 1 & 46 & $0.024^{*}$ \\
\hline & - & $\begin{array}{l}\text { Middle } \quad \text { Age } \\
\text { Adult }\end{array}$ & 42 & 28 & 10 & 80 & \\
\hline & - & Older Adult & 20 & 14 & 8 & 42 & \\
\hline & Total & & 97 & 52 & 19 & 168 & \\
\hline \multirow[t]{3}{*}{ Gender } & - & Male & 59 & 20 & 7 & 86 & $0.014^{*}$ \\
\hline & - & Female & 38 & 32 & 12 & 82 & \\
\hline & Total & & 97 & 52 & 19 & 168 & \\
\hline Educational & - & Never & 8 & 6 & 6 & 20 & $0.047^{* *}$ \\
\hline \multirow[t]{4}{*}{ Level } & - & Primary & 18 & 16 & 6 & 40 & \\
\hline & - & Secondary & 53 & 22 & 6 & 81 & \\
\hline & - & Higher & 18 & 8 & 1 & 27 & \\
\hline & Total & & 97 & 52 & 19 & 168 & \\
\hline Marital & - & Single & 29 & 7 & 1 & 37 & $0.012^{*}$ \\
\hline \multirow[t]{2}{*}{ Status } & - & Married & 68 & 45 & 18 & 131 & \\
\hline & Total & & 97 & 52 & 19 & 168 & \\
\hline
\end{tabular}

${ }^{*}$ Pearson Chi Square, "Likelihood ratio*

Table 6: Comparison between Level of Satisfaction of Patient according to Type of APS Used

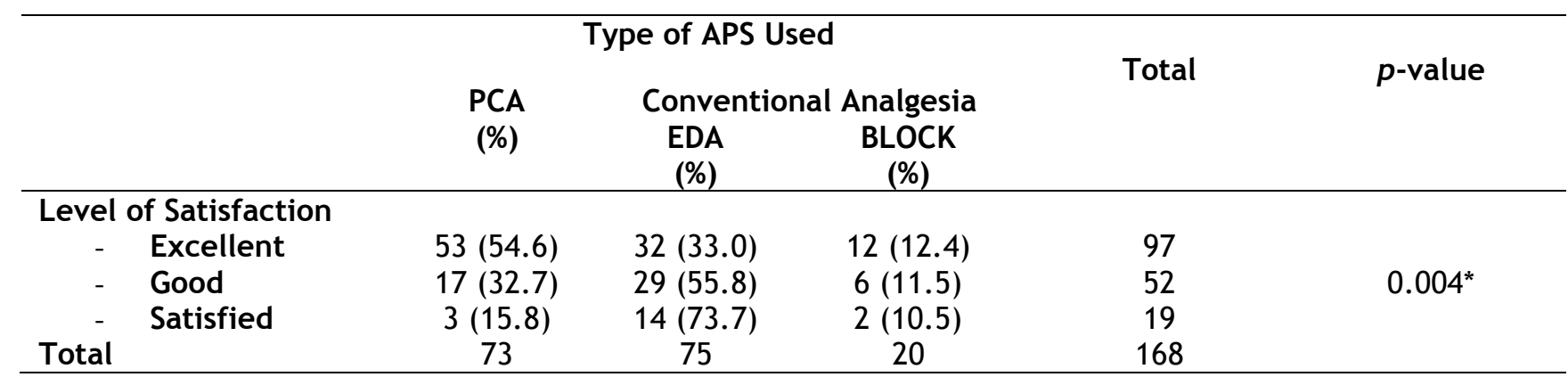

${ }^{*}$ Pearson Chi Square

Education is very important to human lives as it gives people knowledge and skills. Based on the findings of this study majority of patient that has secondary education rated the APS as excellent $(54.6 \%)$ and good $(42.3 \%)$. Meanwhile for the satisfied level, the frequency is rated same by patients with primary, secondary and never been to school. People with high education level usually tend to be more demanding, meanwhile low educational level can cause low understanding related to pain management. Patients appeared comfortable managing their pain medication and made regimen changes based on their personal experiences or preferences, the opinions of others, and the medical knowledge they possessed ${ }^{15}$.

In term of marital status, there is significant different between marital status and level of patient's satisfaction. Majority of married patients have rated APS as excellent compare to single patients. Married couple has an external psychosocial and psychological support in reducing anxiety and managing their pain. An anxious state has been advocated as a factor in lowering pain threshold ${ }^{11}$. Psychological wellbeing is of great significance for the experience of pain after surgery, and psychological preparation of patients undergoing surgery has been shown to shorten hospital stay and to reduce the need for postoperative analgesics ${ }^{3}$.

According to the results of this study, PCA have highest percentage in excellent satisfaction level compare to EDA and BLOCK. PCA was more accepted because it is self-administered based on patient's pain and demand. Compared with the other method, the PCA group of Chinese patients in the 
current study reported significantly higher acceptability and preference for this self-controlled type of pain management ${ }^{2}$. Twenty-one trials with 1260 patients were analysed and none of the studies demonstrated that patients were more satisfied with conventional treatment $^{8}$. Additionally, satisfaction would have been influenced by the ability of PCA to maintain a near constant level of analgesia and to avoid the over or undershooting that leads to the peaks and troughs of analgesia level associated with conventional analgesia ${ }^{2}$. In comparing both techniques in term the total cost, the cost for PCA is more expensive than EDA.

It is very impossible to have zero side effect of drugs for pain management. However, lesser side effect is better. Based on side effect parameter, it showed that PCA was more effective in managing side effect by using factorize technique. However, after using normalize technique, the pain relieving is better with EDA compare to PCA. By comparing the patient's satisfaction towards the services, PCA was favoured the most as it showed the highest percentage of having excellent rate. Therefore, the results of this study suggesting that PCA provides more effective management of pain in postoperative patients as a whole. A study had reported that PCA is more effective than conventional morphine administration in reducing pain at rest and with movement ${ }^{16}$. Same goes to this study.

The equipment of PCA regimen is more expensive compared to the conventional EDA regimen. Despite of the fact that PCA is more expensive, based on the data for this study the patients were favoured PCA more than the EDA. There is one study supported that the PCA-treated patients expressed higher satisfaction and pain relief compared to intramuscular pain management ${ }^{2}$. EDA technique, it appeared to be among the expensive but still it is cheaper than PCA. However, in terms of patient satisfaction, it did not achieve a better satisfaction but EDA give better relieving. In contrast, other study stated that EDA has been identified as the more expensive treatment strategy, but it was shown to be more effective in comparison with PCA in terms of pain-free days ${ }^{17}$.

\section{CONCLUSION}

In summary, every drug has its own side effects. As the healthcare provider, it is a need to ensure drugs that were given to the patients are at the very minimum risk of having the side effects. Based on the findings of this study, it could be said that both drugs have lower percentage of people experienced the side effect after treated with the drugs. Therefore, the future study should be more focusing on the side effect of the drugs used. In terms of cost spent for the methods, the PCA regimen is more likely expensive compared to the conventional methods. However, based on survey among the patients, PCA-treated patients expressed higher satisfaction compared to the conventional regimen of pain management.

\section{ACKNOWLEDGEMENT}

This study was financially supported by the International Islamic University Malaysia with grant number FRGS15-253-0494.

\section{REFERENCES}

1. James DN Guidelines for the provision of anaesthetic services. Anaesthesia services for acute pain management. 2014.

2. Chang AM, Cheung TH, Ip WP. Patientcontrolled analgesia versus conventional intramuscular injection: a cost effectiveness analysis. J. Adv. Nurs 2004;46:531-41.

3. Wickstrom, KE. Postoperative pain management: predictors, barriers and outcome. J Clin Nurs 2008.

4. Madeira I, Frada R, Marvao J, et al. (2009). Morphine patient-controlled analgesia for postoperative analgesia in patients who have transplanted cadaver donor kidneys. Transplant Proc. 2011; 43(1):125-30.

5. Walder B, Schafer M, Henzi I, et al. Efficacy and safety of patient-controlled opioid analgesia for acute postoperative pain: a quantitative systemic review. Acta Anaesthesiol Scand 2001;45: 795804.

6. Weatherspoon D. Pain Scale: What It Is and How to Use It [Internet]. Healthline. 2017 [cited 8 July 2019]. Available from: https://www.healthline.com/health/pa in-scale

7. Munro AJ, Long GT, Sleigh JW, Stat D. Nurse-Administered Subcutaneous Morphine Is a Satisfactory Alternative to Intravenous Patient-Controlled Analgesia Morphine After Cardiac Surgery. 1998;711.

8. Hudcova J, McNicol ED, Quah CS, et al. patient controlled opioid analgesia versus conventional opioid analgesia for 
postoperative pain. Cochrane Database Syst Rev. 2006;(4):CD003348.

9. Aging changes in the senses: MedlinePlus Medical Encyclopedia [Internet]. Medlineplus.gov. 2019 [cited 8 July 2019]. Available from: https: / / medlineplus.gov/ency/article/0 04013.htm

10. Ozalp G, Sarioglu R, Tuncel G, et al. Preoperative emotional states in patients with breast cancer and postoperative pain. Acta Anaesthesiol Scand 2003; 47(1):26-9.

11. Vivian HYI, Abrishami A, Peng PWH, et al. Predictors of postoperative pain and analgesic consumption: a qualitative systematic review. Anesthesiology 2009; 111: 657-77.

12. Traub RJ, Ji Y. NIH Public Access. Front Neuroendocrinol. 2014;34(4):1-40.

13. Apfelbaum JL, Chen C, Gan TJ, et al. Postoperative pain experience: results from a national survey suggest postoperative pain continues to be undermanaged. Anesth Analg 2003;97: 534-540.

14. Alabas OA, Tashani OA, Tabasam G, Johnson MI. Gender role affects experimental pain responses: A systematic review with meta-analysis. 2012;16:1211-23.

15. Bremner S, Webster F, Katz J, et al. A qualitative descriptive study: older adults' postoperative pain medication usage after total knee arthroplasty. J Opioid Manag. 2012;8(3):145-52.

16. Keita H, Geachan N, Dahmani S, et al. Comparison between patient-controlled analgesia and subcutaneous morphine in elderly patients after total hip replacement. Br. J. Anaesth. 2003; 90(1):53-57.

17. Tilleul $P$, Aissou $M$, Bocquet $F$, et al. Cost-effectiveness analysis comparing epidural, patient-controlled intravenous morphine, and continuous wound infiltration for postoperative pain management after open abdominal surgery. Br. J. Anaesth. 2012;1-8. 